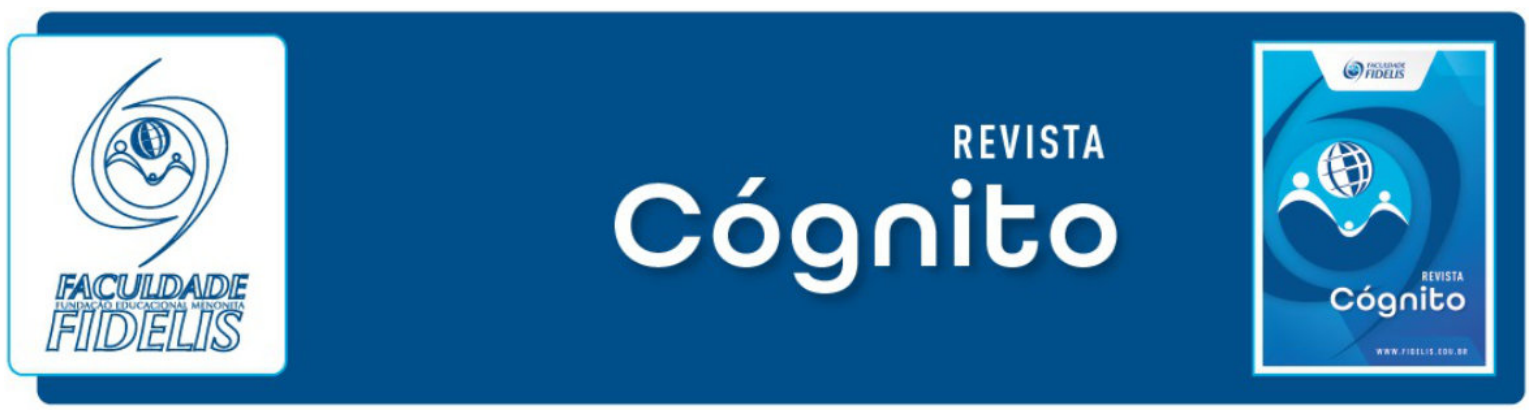

\title{
A IMPORTÂNCIA DA UTILIZAÇÃO DO MATERIAL DOURADO NA EDUCAÇÃO DE JOVENS E ADULTOS
}

\author{
Jamile Ilheus do Nascimento ${ }^{1}$ \\ Reginaldo Aparecido de Oliveira ${ }^{2}$
}

\section{RESUMO}

O presente artigo tem por objetivo discutir sobre a relevância da utilização do material dourado para o ensino de matemática da Educação de Jovens e Adultos (EJA), trata-se de uma pesquisa qualitativa, baseada em um relato de experiência de uma turma de EJA. A análise foi realizada com 8 estudantes com faixa etária no intervalo de 30 e 60 anos da modalidade presencial. Os dados foram levantados por meio de observações e registros no decorrer da abordagem didática da Escola de Ensino Fundamental Professor Germano Paciornik, situada em Curitiba. Os relatos foram organizados de modo cronológico descrevendo assim como as práticas pedagógicas conduziram a acontecimentos que por sua vez levaram a utilização do material dourado como recurso pedagógico inovador naquele contexto observado como um material desconhecido pelos estudantes que não conheciam e não possuíam acesso ao material dourado como recurso para a aprendizagem. Buscou-se contemplar durante a Revisão de Literatura autores como Azevedo (1979); Deneca e Pires (2019); Lorenzato (2006) os quais significaram e deram sentido a relevância do material dourado durante o ensino da EJA. Para análise e discussão, foram estabelecidos alguns parâmetros frente aos distanciamentos e aproximações na abordagem didática docente e as reações dos estudantes ao longo do relato. Por fim, foram pontuadas as considerações finais diante de todo conteúdo trabalhado e das vivências exploradas no decorrer do processo.

Palavras-chave: Educação de Jovens e Adultos; Prática Pedagógica; Material Dourado.

${ }^{1}$ Discente do Curso de Licenciatura em Pedagogia da Faculdade Fidelis - Curitiba/PR

${ }^{2}$ Mestre em Educação pela Universidade Federal do Paraná, Docente do Curso de Licenciatura em Pedagogia da Faculdade Fidelis. E-mail: reginaldo.oliveira@fidelis.edu.br 


\section{INTRODUÇÃO}

A Educação de Jovens e Adultos (EJA) durante os anos de sua história tem sido caracterizada como um espaço de formação de estudantes que não conseguiram completar seus estudos no tempo adequado, agrupando assim, uma vasta diversidade de histórias de vida, como também uma infinidade de motivadores que levam as pessoas a retornarem seus estudos nas idades mais variadas. Tal situação interfere diretamente na organização da prática pedagógica, uma vez que o professor precisa estar atento ao contexto específico e fazer mão de recursos que possam contribuir com a formação de cada estudante.

O presente artigo tem por objetivo discutir sobre a relevância da utilização do material dourado para o ensino de matemática da Educação de Jovens e Adultos (EJA), trata-se de uma pesquisa qualitativa, baseada em um relato de experiência de uma turma de EJA. A análise foi realizada com 8 estudantes com faixa etária no intervalo de 30 e 60 anos da modalidade presencial. Os dados foram levantados por meio de observações e registros no decorrer da abordagem didática da Escola de Ensino Fundamental Professor Germano Paciornik, situada em Curitiba. Os relatos foram organizados de modo cronológico, descrevendo assim, como as práticas pedagógicas conduziram a acontecimentos, que por sua vez, levaram a utilização do material dourado como recurso pedagógico inovador naquele contexto, observou-se que era uma ferramenta desconhecida pelos estudantes além de não possuírem acesso ao material como recurso para a aprendizagem.

Buscou-se contemplar durante a Revisão de Literatura autores como Azevedo (1979); Deneca e Pires (2019); Lorenzato (2006) os quais significaram e deram sentido a relevância do material dourado durante o ensino da EJA, contribuindo com a percepção da primordialidade para um bom desenvolvimento acadêmico e pedagógico. No decorrer dos resultados, apresentou-se o relato de experiência que instigou a realização do tema. Para análise e discussão, foram estabelecidos alguns parâmetros frente aos distanciamentos na abordagem didática docente e as reações dos estudantes ao longo do relato. Por fim, foram pontuadas as considerações finais diante de todo conteúdo trabalhado e das vivências exploradas no decorrer do processo.

\section{REVISÃO DE LITERATURA DA EJA E DO MATERIAL DOURADO}

A Educação de Jovens e Adultos (EJA) refere-se ao ensino fornecido pela rede pública brasileira, a fim de desenvolver o ensino fundamental e médio para pessoas que não possuem idade para o ingresso nas etapas ditas convencionais, e falta de oportunidade, principalmente ao se tratar de cunho financeiro e de questões de classe social, proporcionando acesso à educação a quem não 
teve oportunidades para exercê-lo, permitindo que o indivíduo retome aos estudos e os conclua em um tempo menor, qualificando-o para a carreira profissional e para sua vida. Bem como aborda a LDB 9394/96 Art. 37:

\begin{abstract}
A educação de jovens e adultos será destinada àqueles que não tiveram acesso ou continuidade de estudos nos ensinos fundamental e médio na idade própria e constituirá instrumento para a educação e a aprendizagem ao longo da vida. $\S 1^{\circ}$ Os sistemas de ensino assegurarão gratuitamente aos jovens e aos adultos, que não puderam efetuar os estudos na idade regular, oportunidades educacionais apropriadas, consideradas as características do alunado, seus interesses, condições de vida e de trabalho, mediante cursos e exames. (BRASIL, 1996)
\end{abstract}

A característica do público atendido para essa modalidade são trabalhadores, empregados ou não, indivíduos que não tiveram acesso à cultura letrada, havendo um elevado índice de evasão escolar, desenvolvendo suas competências de modo inapropriado e com senso crítico reduzido. Muitos são os fatores que levam a tais fracassos, dentre eles aspectos sociais, falta de condições financeiras, psicológicas e motivacionais, tanto decorrente de experiências desagradáveis em sala, possibilitando uma trava no ensino por um desafio de compreensão dos conteúdos e até mesmo vergonha, afinal, muitos brasileiros chegam a sua fase adulta passando apenas, pela fase de alfabetização, havendo casos em que alguns nem essa modalidade não tiveram acesso.

Em se tratando de acesso, é possível notar que muitos recursos didáticos não são considerados viáveis para o ensino da EJA, muitos deles essenciais para uma melhor compreensão do ensino de diversas disciplinas, dentre elas a disciplina de matemática. Um dos possíveis recursos trata-se do Material Dourado, criado pela médica e educadora italiana Maria Montessori, inicialmente com o intuito de auxiliar crianças com necessidades especiais, entretanto de forte impacto a todos os estudantes, desde os pequenos aos mais adultos. O material é formado por quatro peças: cubo pequeno, barra, placa, cubo ou bloco. Para realizar cálculos matemáticos com o Material Dourado é utilizado o "quadro valor lugar", ou o chamado ábaco de papel. Segundo Azevedo (1979, p. 27) Montessori relata que "nada deve ser dado à criança, no campo da matemática, sem primeiro apresentar-se a ela uma situação concreta que a leve a agir, a pensar, a experimentar, a descobrir, e daí, a mergulhar na abstração". Diante disso, é possível observar que o Material Dourado possui percepções visuais e táteis auxiliando, de acordo com Deneca e Pires (2019, p. 12), "na exploração dos seguintes conteúdos matemáticos: sistema de numeração decimal, representação decimal dos números racionais, números fracionários, operações aritméticas, volume, área, conceitos geométricos, e outros".

Assim, o Material Dourado possui como objetivo fornecer ao estudante uma percepção abrangente em torno das relações de adição, subtração, entre outros, partindo de cálculos abstratos 
até cálculos com os materiais mais concretos, no caso, as peças do Material Dourado, o que Lorenzato (2006, p. 21) defende relatando que o material concreto "pode ser um excelente catalizador para o aluno construir o seu saber matemático", compreendendo assim princípios de agrupamento, reagrupamento, e troca entre as numerações decimais.

\section{RESULTADOS}

Durante a aula do dia 16 de maio de 2019, havia 8 estudantes todas do sexo feminino, com faixa etária no intervalo de 30 e 60 anos, as quais possuíam experiência escolar de quando pequenos ou depois de adultos, ou ambas as idades, com experiências escolares anteriores desestimulantes e de estudo tradicional, mecanizado.

Nesta aula as estudantes da EJA estavam um pouco eufóricas ao relatarem as dificuldades apresentadas diante da realização dos cálculos matemáticos envolvendo subtração, não compreendendo o percurso das centenas para as dezenas, e das dezenas as unidades. Diante disso, houve a necessidade de intervir relatando alguns processos realizados com o Material Dourado para uma maior compreensão dos cálculos. Realizaram-se diversas representações da utilização do recurso primeiramente no quadro, a fim de observarem o formato do material e criarem o desejo e a curiosidade de vê-lo de modo concreto e manipulativo, envolvendo alguns cálculos matemáticos que as estudantes estavam com dificuldades.

A docente da turma relatou que não costumava utilizar o Material Dourado durante as aulas, pois diz ser um recurso de uso infantil e desinteressante ao aprendizado dos estudantes da EJA em sua prática educativa.

O que tornou chocante foi o fato das estudantes nunca terem ouvido falar sobre o recurso, o que dificultou ainda mais o entendimento. Ao realizar uma pequena amostra de como utilizar tal material, as mesmas ficaram perplexas por nunca terem ouvido falar desse recurso essencial para aprendizagem matemática, relatando que aprenderam os conteúdos da disciplina em seus antigos contatos acadêmicos de maneira mecânica e direta, sem abordar todo processo envolvido nos cálculos de adição e subtração.

Em seguida, as estudantes puderam manipular o ilustre recurso didático, a fim de compreenderem sua utilização, importância e de algum modo associarem aos frequentes cálculos que fazem na resolução matemática. As estudantes, durante a representação, indignaram-se por nunca ter utilizado o Material Dourado antes, e sentiram-se frustradas por compreenderem tão pouco e não conseguirem se adequar a outra metodologia de ensino, senão a tradicional a qual, 
infelizmente, já estavam habituadas. Entretanto, ao observar que há diferentes possibilidades e processos para atingir um mesmo resultado, surpreenderam-se e se entusiasmaram em descobrir mais sobre diferentes tipos de recursos.

\section{ANÁLISE E DISCUSSÃO}

Durante a experiência, infelizmente é notório que há um distanciamento gritante com relação a utilização do Material Dourado na EJA, já que, mesmo com diversos autores defendendo a importância de se estabelecer recursos que possibilitem associações com a realidade, à conscientização do sujeito, em seu contexto, dando ênfase na aprendizagem histórica, trazendo significado e aplicação no cotidiano, engajando-os em situações concretas de experimentação e manipulação. Foi visto que a docente ainda aborda um ensino repleto de abstrações e mecanizações, onde o estudante torna-se apenas o receptor do conhecimento, não sendo o protagonista de sua própria construção da aprendizagem, impossibilitando suas diferentes formas de pensar com criticidade, compreender processos matemáticos, principalmente tratando do Material Dourado, haja vista sua grande relevância para transformação do conhecimento.

Com isso, foi possível observar que ao iniciar um conteúdo, o docente deve possuir um planejamento adequado com diversos recursos a serem utilizados não somente como forma de abordagem didática, mas também como "cartas na manga" se caso algum estudante possua dificuldade na compreensão do ensino como ocorreu na descrição do relato de experiência abordado, a fim de atingir os objetivos de seu plano de maneira harmoniosa e satisfatória. Entretanto, é preciso salientar que não é coerente apenas obter determinados recursos didáticos em sala de aula, sem a devida compreensão de sua importância e utilidade em todo ensino de Educação Básica até a Educação de Jovens e Adultos. Sendo assim, cabe ao professor se especializar em metodologias diversificadas, explorar conteúdos que enriqueçam os estudantes de cultura e protagonismo em sala por meio de materiais concretos/manipulativos que desenvolvam o senso crítico, compreensões significativas na assimilação dos conteúdos.

\section{CONSIDERAÇÕES FINAIS}

É indiscutível a importância de uma prática docente nas turmas de Educação de Jovens e Adultos que possibilitem aos estudantes uma aproximação concreta e prática com os conteúdos que devem ser trabalhados. Um dos grandes elementos desta discussão é a construção de uma prática pedagógica que possa atender as especificidades do adulto que retorna para contextos 
formativos de educação básica, certamente se faz necessário o contínuo de práticas que envolvem a utilização dos mais diversos materiais buscando assim desmistificar uma compreensão de que os materiais são unicamente de uso em contextos infantis, possibilitando assim novas abordagens que de fato possibilitem aprendizagens.

Outro ponto importante em que se pode observar é a importância da didática do professor em cada assunto trabalhado, a segurança que o professor da EJA precisa passar aos estudantes para que os mesmos possam aprender e compreender aquilo que está sendo ensinado. Todo professor precisa estar estudando sempre, atualizando-se, buscando métodos diversificados para o ensino, métodos que chamem a atenção dos alunos, sendo de suma importância, tanto para o docente, quanto para o discente.

\section{REFERÊNCIAS}

AZEVEDO, Edith D. M. Apresentação do trabalho Montessoriano. In: Ver. de Educação \& Matemática no. 3, 1979 (pp. 26 - 27).

BRASIL. Ministério da Educação. Lei de Diretrizes e Bases da Educação Nacional. Secretaria de Educação Básica. Brasília MEC/SEB, 1996.

DENECA, M de L., PIRES, M. N. M. O ensino da atemática com auxílio de materiais manipuláveis. Disponível em: $<$ http://www.diaadiaeducacao.pr.gov.br/portals/pde/arquivos/6254.pdf>. Acesso em: 14 jun. 2019.

LORENZATO, S. A.. Laboratório de ensino de matemática e materiais didáticos manipuláveis. In: LORENZATO, Sérgio (org.). O Laboratório de ensino de matemática na formação de professores. Campinas: Autores Associados, 2006. 